\title{
Papaverine Induced Priapism - A Case Report
}

\author{
Dr Sanjana Gopal ${ }^{1}$, Dr Naveen $\mathbf{H}^{2}$, Dr Ashutosh Sahewalla ${ }^{3}$ \\ ${ }^{1}$ Post Graduate Student, Department of general surgery, JJM Medical College, Davangere \\ ${ }^{2}$ Professor, Department of General Surgery, JJM Medical College, Davangere \\ ${ }^{3}$ Post Graduate Student, Department of General Surgery, JJM Medical College, Davangere
}

\begin{abstract}
Priapism is a pathological condition of prolonged penile erection not related to sexual stimulation, it can follow intracorporeal injection in $2-18 \%$ of patients depending on pharmacostimulation ${ }^{1}$. In papaverine inductions, prolonged erections have been reported in 5-35\% of patients ${ }^{2}$. We are hereby reporting one such case of papaverine induced priapism occurring in a 28 year old male patient with erectile dysfunction.
\end{abstract}

Keywords: Intracorporeal, Papaverine Induced Priapism, Erectile Dysfunction

\section{Introduction}

Priapism describes a persistent penile erection arising from dysfunction of the mechanisms regulating penile tumescence, rigidity, and flaccidity unrelated to sexual stimulation. A correct diagnosis of priapism is amatter of urgency requiring identification of the underlying hemodynamics. Intracavernous papaverine/phentolamine induced priapism can be accurately predicted with color Doppler ultrasonography ${ }^{3}$

\section{Case Report}

A 28 year oldmale patient about to get married presented to the Psychiatry OPD with complaints of difficulty in erection since 2 years which increased in the last 1.5 months. Patient was a $\mathrm{k} / \mathrm{c} / \mathrm{o}$ BPAD and on treatment for the same. Patient was admitted in Psychiatry ward. Penile Doppler was done which was found to be normal. Following which left intracavernosal Papaverine $60 \mathrm{mg}$ was given after valid consent. Patient developed persistent erection which did not subside.

Patient was referred to Urology after 20hours of persistent erection. On examination, patient was found to have erect, rigid penis with tenderness.

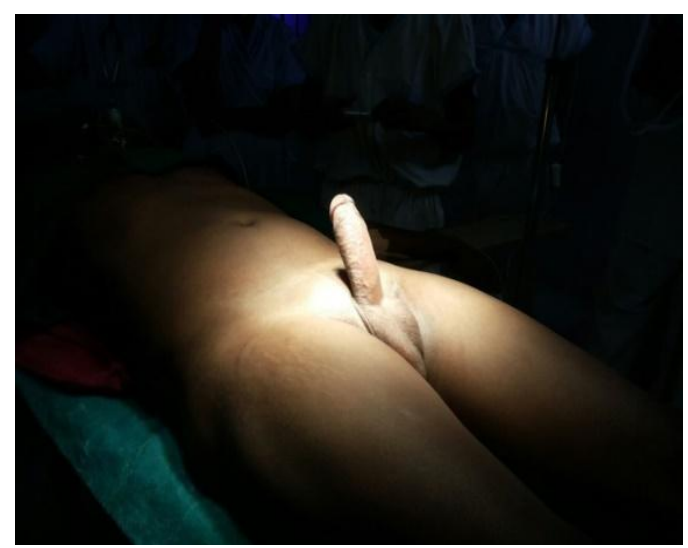

Patient was then planned for corporal irrigation under spinal anesthesia which if failed was proposed for shunt surgery. Diagnosis of low flow priapism was made. Under spinal anesthesia patient was put in supine position, a transcavernosal 18 gauge needle was placed percutaneously into the lateral aspect of proximal penile shaft. Aspiration and evacuation of decongested blood from corpora cavernosa was performed. Compression was applied and aspiration repeated.

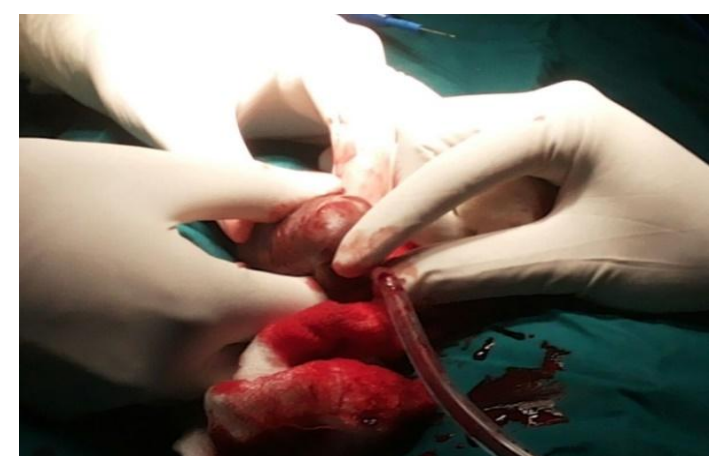

Wash was given with 1:50,000 Adrenaline until penis became flaccid.

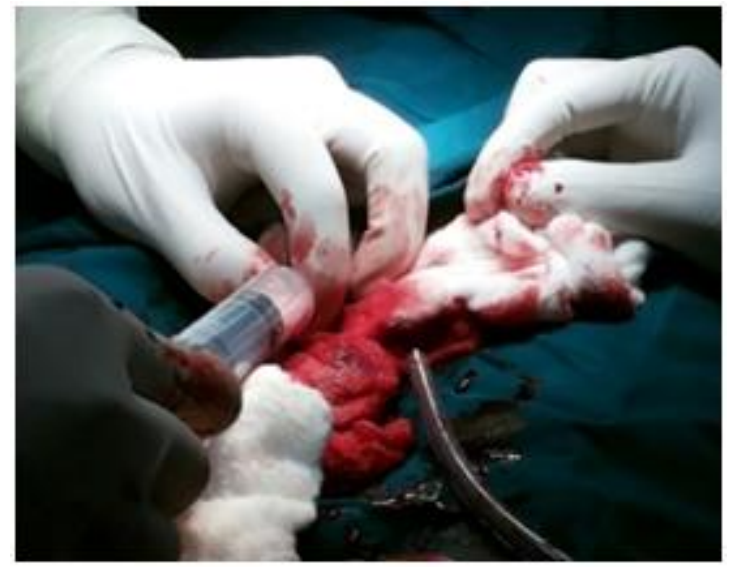




\section{International Journal of Science and Research (IJSR) \\ ISSN (Online): 2319-7064}

Index Copernicus Value (2015): 78.96 | Impact Factor (2015): 6.391

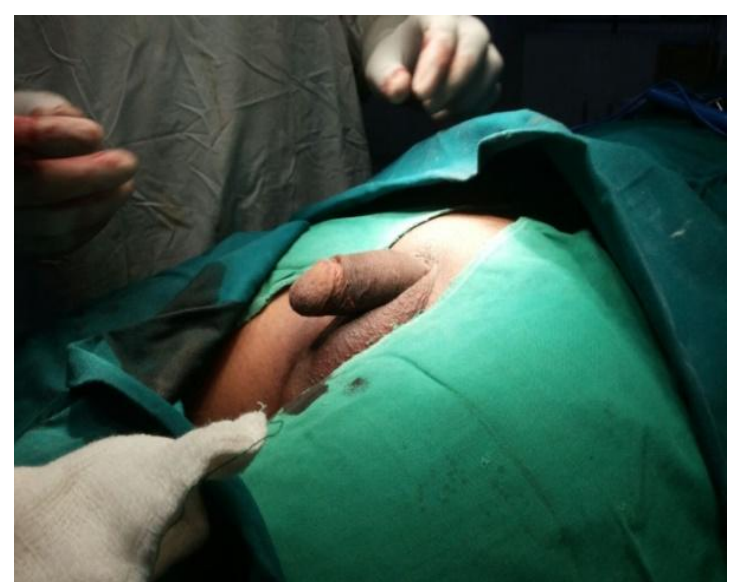

These maneuvers were serially repeated. Foley's catheterization was done. Post-operative period was uneventful. Catheter was removed the next day. Patient was discharged after two days.

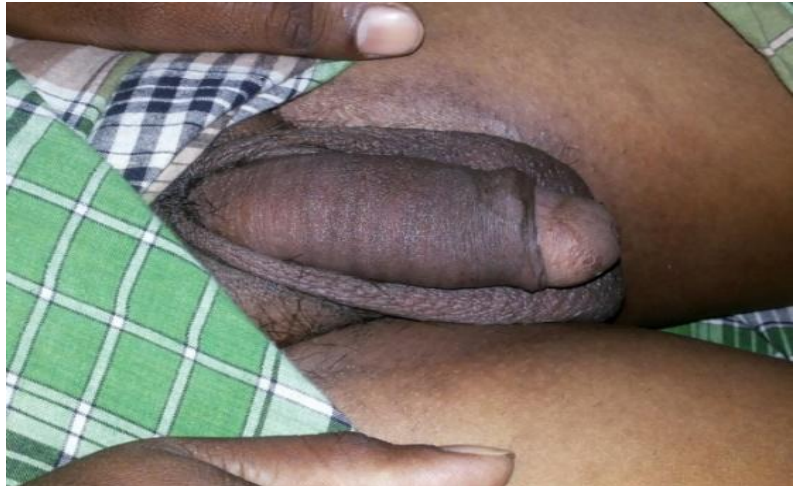

\section{Discussion}

Priapism is a full or partial erection that continues morethan 4 hours beyond sexual stimulation and orgasm oris unrelated to sexual stimulation. The term priapism has its origin in reference to the Greek god Priapus, who was worshipped as a god of fertility and protector of horticulture. Priapus is memorialized in sculptures for his giant phallus.

Veno-occlusive priapism is a condition which requires prompt effective emergency treatment in order to avoid long-term erectile dysfunction (ED). Before the advent of intracavernosal pharmacotherapy for ED, the most common causes were the hyperviscosity syndromes, psychotropic medications and malignant infiltration.

Penile colour Doppler sonography is a valuable method for evaluation of erectile dysfunction. However, there are some concerns about the safety of this method due to intracorporeal injection of papaverine which may cause priapism as a complication resulting in penile fibrosis.

However, in 1982, Viragand, in 1983, Brindley showed that penile tumescence could be induced by the intracorporeal injection of vasoactive drugs such as papaverine, phentolamine and phenoxybenzamine. Subsequently, these agents were used in treating ED.

In a study by $\mathrm{C}$ M EARLE over a span of 16 years, most episodes of priapism were related to ICI therapy for erectile dysfunction and the majority of these were associated with papaverine or papaverine containing combinations such as double and triple mix have been shown to carry a greater risk of priapism. However the incidence of priapism fell sharply after the institution of PGE1 monotherapy ${ }^{4}$.

It has been suggested that those patients who are particularly at risk of priapism with ICI therapy are younger men with better baseline erectile function, or those with a psychogenic or neurogenic cause for ED. Patients with a history of coronary artery disease have a significantly lower risk of priapism, as do patients with vasculogenic ED compared with neurogenic ED. However, all patients are at potential risk $^{5}$.

The time between onset and presentation ranged from 4 to $96 \mathrm{~h}$ (mean $16.5 \mathrm{~h}$ ) and proved to be the major determinant of whether a surgical shunt was required. The delay to presentation in some patients is a concern. This may occur when the patient is unaware of the seriousness of the disorder, may assume that the condition will resolve spontaneously or feels embarrassed about presenting. Delay to presentation is of particular concern when it happens in the setting of ICI, where priapism is a known and serious complication. Clear advice about the possibility and the consequences of priapism should be given by the treating doctor.

\section{Treatment}

\section{Non-Invasive (Conservativetherapy)}

It was found that physical exercise and oral salbutamol are safe and effective in restoring detumescence of pharmacologically induced priapism wherein the positive response rate noted was $73 \%{ }^{6}$.

\section{1) Medical :}

a) Oral sympathomimetic drugs (ephedrine, Pseudoephedrine, Phenylpropanolamine, and Terbutaline) have been reported to effectively reverse prolonged erection ( $<4$ hours) initiated by intracavernous injection therapies with efficacies of $28 \%$ to $36 \%$.

b) Intracavernosal Injection of Phenylephrine.

c) Corporal Aspiration with Irrigation.

2) Surgical

a) Percutaneous Distal Shunt-Ebbehoj,Winter's or T-shunt - CAVERNOGLANULAR SHUNT.

b) Open Distal Shunt- Al-Ghorab or Corporal Snake CAVERNOGLANULAR SHUNT.

c) Open Proximal Shunt- Quackel's or Sacher - CORPUS CAVERNOSUM to SPONGIOSUM SHUNT.

d) Saphenous Vein - Grayhack - VEIN ANASTOMOSED to CORPUS CAVERNOSUM.

e) Deep Dorsal Vein Shunt - Barry - VEIN ANASTOMOSED to CORPUS CAVERNOSUM ${ }^{7}$

\section{Conclusion}

Priapism is considered Urologic Emergency and should be treated prompt and consequently. The treatment options for all types of priapism are initially conservative but surgical therapy must be available when applicable. Emergent 


\section{International Journal of Science and Research (IJSR) \\ ISSN (Online): 2319-7064}

Index Copernicus Value (2015): 78.96 | Impact Factor (2015): 6.391

intervention is required with the predominant course to achieve smooth muscle constriction via corpora cavernosal aspiration/irrigation with concomitant use of a sympathomimetic agent. Alpha adrenergic agents have been shown to be effective in the treatment of priapism resulting from intrapenile injections of vasoactive drugs (such as Papaverine, Phentolamine, or prostaglandin E1), which are used for the treatment of impotence. As stated above these have quick results and can be used as first line management in priapism.

\section{References}

[1] Lomas GM, Jarrow JP. Risk factors for papaverine induced priapism. J Urol 1992; 147:1280-1281.

[2] Broderick GA, Kadioglu A, Bivalaqua TJ et al. Priapism: pathogenesis, epidemiology and management. J sex Med 2010; 7(1pt2):476-500.

[3] Bahgat Metawea, Abdel Rehman El Nashar et al. Intracavernous Papaverine/ phentolamine induced priapism can be accurately predicted with color Doppler: oct 2005: vol 66: 858-860.

[4] C.M. Earle, B.G.A Stuckey et al: the incidence and management of priapism in WesternAustralia: 16 year audit; International journal of Imptence Research: 2003(15); 272-276.

[5] Nellans RE, Ellis LR, Kramer-Levien D. Pharmacological erection: diagnosis and treatment applications in 69 patients. $J$ Urol 1987; 138: 52-54.

[6] Mohamed Habous , Mohammed Elkhonly et al. Noninvasive treatment for iatrogenic priapism: Do they really work? A Prospective Multicenter Study 2016; vol 8:193-196.

[7] Montague DR, Jarrow J, Broderick GA et al. American Urological Association guideline on Management of Priapism: J Urol 2003;170 (4pt 1);1318-24. 